\title{
The Rolling Tool Development in Order to Improve the Geometry of a Tube Profile and to Reduce the Wear of Mill Rolls
}

\author{
Marcin Knapinski \\ Czestochowa University of Technology, Poland \\ Yuri L. Bobarikin, Yaroslav I. Radkin \\ P.O. Sukhoi State Technical University of Gomel, \\ Republic of Belarus
}

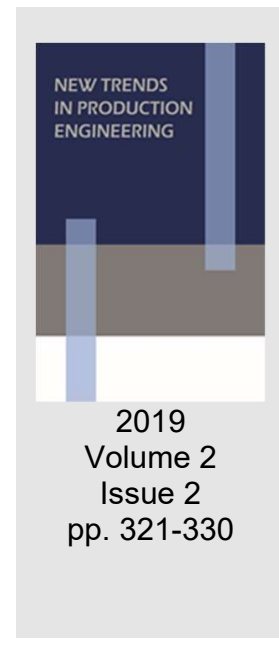

Date of submission to the Editor: 09/2019

Date of acceptance by the Editor: 11/2019

\section{INTRODUCTION}

Increasing the accuracy of the geometrical parameters of tube profiles is one of the priority areas of modern tube industry. Therefore, research and developments are advanced when they are aimed at improving the technology of the rolling of seamless tubes that let improve the accuracy of the geometrical parameters of hot-deformed seamless tubes.

In world practice, tube-rolling units with continuous mills of lengthwise rolling have received wide acceptance. The technology consists of several stages and includes a number of operations, such as obtaining a tubular billet on piercing mill, obtaining a rough tube by lengthwise rolling on a continuous reeling mill, the rolling of a rough tube on a stretch reducing mill to obtain a final tube profile and cold or warm straightening for increasing the straightness of the tube (Danchenko et al., 2002, Dukmasov, 2001).

Obtaining of a rough tube on a continuous mill is an important phase since the main properties which affect the quality of the finished product are laid exactly during the elongating process. The formation of the wall thickness and of the geometry of the rough tube profile in the calibers of a reeling mill determines the nature of variation in wall thickness and deviations of the geometrical parameters of the finished tube profile from the set-up parameters (Danchenko et al., 2002, Dukmasov, 2001, Pavlov \& Erpalov, 2019, Reggio et al., 2002, Tang et al., 2018, Wanga et al., 2014).

During continuous elongating process the deformation of the tube wall occurs between the rolls of the rolling stands and the mandrel, which moves in the direction of rolling at a given speed. The reeling mill consists of five three roll stands which are arranged in series (Fig. 1). The first stand is designed to the reduction of the tubular billet on the mandrel, the main metal deformation occurs on the second and the third stands, the fourth and the fifth stands are calibrating ones and designed to form the final profile of the rough tube. 


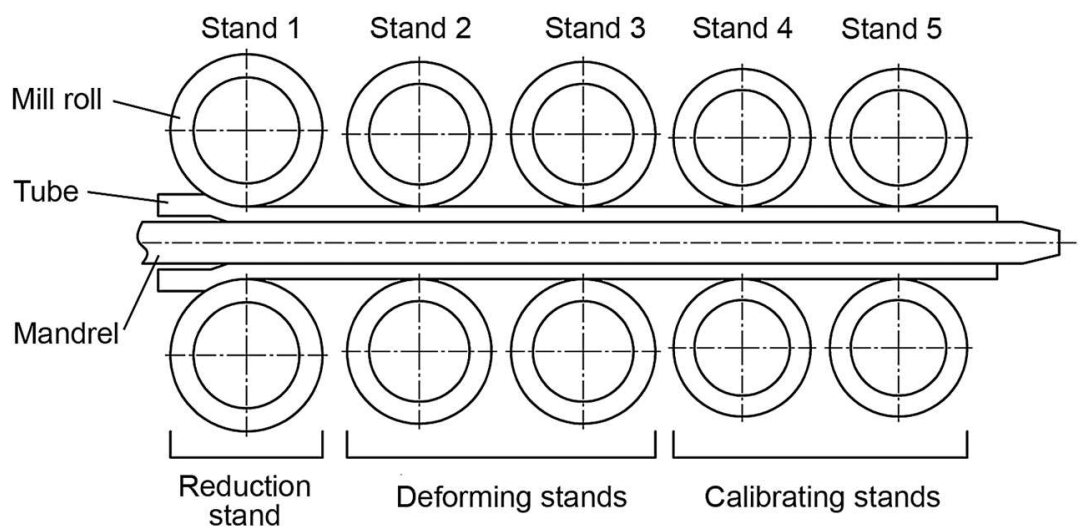

Fig. 1 Scheme of the arrangement of the continuous reeling mill stands

In modern practice, in order to improve the uniformity of the reduction of the billet, the stands with three rolls are the most widespread (Fig. 2).

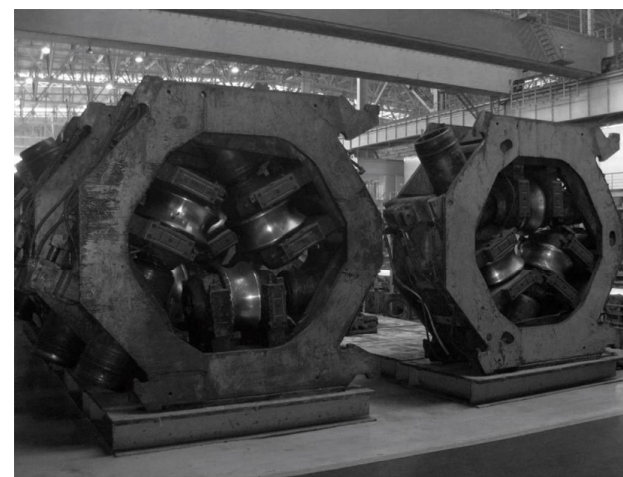

a)

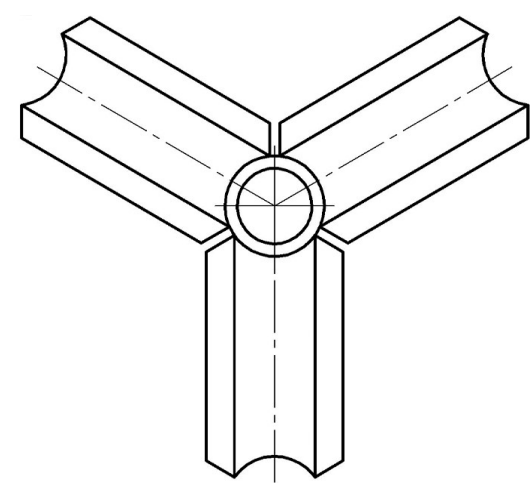

b)

Fig. 2 Three rolls stand of the reeling mill

a) general view of a stand; b) scheme of the arrangement of the rolling stand rolls

The profile of the calibers of rolls of the reeling mill has a significant effect on the distribution of stresses that occur in metal during the deformation process and the formation of the correct geometry of the obtained rough tube.

The work purpose: The determination of the geometry of the mill rolls' calibers of the continuous three roll reeling mill which will reduce the deviation of the geometry of the section of a rough tube from a given profile and will reduce the wear of the contact surface of mill rolls.

\section{METHODOLOGY OF RESEARCH}

The numerical simulation method based on the finite element method was chosen to determine the influence of geometrical parameters of the calibration of mill rolls on the accuracy of rough tubes. This method allows to carry out quite accurate analysis and obtain reliable results on the stress-strain and thermal states of the billet during material processing, it makes it possible to obtain numerical values of stresses, strains and force parameters of the process, and also allows to visualize the results, which is essential for assessing the accuracy of the geometry of the tube profile (Carvalho et al., 2006, Chen et al., 2014, Ji et al., 2017, Jianga et al., 2019, Li et al., 2011, Pater et al., 2006, Pan et al., 2019, Qinghua et al., 2019, Yang et al., 2017). 
An adequate numerical model of the elongating process of rough tubes on a continuous three roll reeling mill was used to study the effect of the shape of calibers on the accuracy of the profile obtained (Bobarikin et al., 2016, Bobarikin et al., 2017). The elongating process of a tubular billet into a rough tube for the production of a $168.3 \times 4.5 \mathrm{~mm}$ tube profile made of steel 20 was studied. The Archard wear model was used to simulate wear and an elasto-plastic model of Mises was used for the material being processed. The problem was solved according to the Euler-Lagrange identity, the friction between the billet and the tool obeys the Amonton-Coulomb law. The initial data for numerical simulation are presented in Tables 1, 2.

Table 1 The table of rolling of the $168.3 \times 4.5 \mathrm{~mm}$ profile production

\begin{tabular}{|c|c|c|c|c|c|c|c|c|}
\hline \multicolumn{2}{|c|}{$\begin{array}{c}\text { Piercing } \\
\text { mill }\end{array}$} & \multicolumn{3}{c|}{$\begin{array}{c}\text { Reeling } \\
\text { mill }\end{array}$} & \multicolumn{2}{c|}{$\begin{array}{c}\text { Mandrel } \\
\text { extraction stand }\end{array}$} & \multicolumn{2}{c|}{$\begin{array}{c}\text { Reduction } \\
\text { mill }\end{array}$} \\
\hline $\mathrm{D}, \mathrm{mm}$ & $\mathrm{S}, \mathrm{mm}$ & $\mathrm{D}, \mathrm{mm}$ & $\mathrm{S}, \mathrm{mm}$ & $\mathrm{D}_{\text {man }}, \mathrm{mm}$ & $\mathrm{D}, \mathrm{mm}$ & $\mathrm{S}, \mathrm{mm}$ & $\mathrm{D}, \mathrm{mm}$ & $\mathrm{S}, \mathrm{mm}$ \\
\hline 215 & 13,8 & 184,3 & 4,38 & 175,4 & 175 & 4,48 & 170 & 4,55 \\
\hline
\end{tabular}

Table 2 Adjusting parameters of the reeling mill for the $168.3 \times 4.5 \mathrm{~mm}$ profile production

\begin{tabular}{|c|c|c|c|c|c|c|}
\hline $\begin{array}{c}\text { Billet } \\
\text { temperat } \\
\text { ure, }{ }^{\circ} \mathbf{C}\end{array}$ & $\begin{array}{c}\text { Mandrel } \\
\text { speed, } \mathbf{~} / \mathbf{s}\end{array}$ & $\begin{array}{c}\text { stand 1 } \\
\text { rev/min }\end{array}$ & $\begin{array}{c}\text { stand 2 } \\
\text { rev/min }\end{array}$ & $\begin{array}{c}\text { stand 3 } \\
\text { rev/min }\end{array}$ & $\begin{array}{c}\text { stand 4 } \\
\text { rev/min }\end{array}$ & $\begin{array}{c}\text { stand 5 } \\
\text { rev/min }\end{array}$ \\
\hline 1080 & 2,3 & 38,25 & 55,95 & 82,06 & 95,48 & 96,94 \\
\hline
\end{tabular}

A set of assumptions have been adopted during model development:

- The friction coefficient over the entire surface of the rolling tool is assumed to be constant;

- Materials of rolls and elongating mandrel is absolutely rigid;

- Before the elongating process the billet has the same temperature at each point.

The following types of calibers are used during the elongating process of rough tubes: round calibers with straight or rounded tapers or oval calibers.

Oval and rounded calibers that are used in three roll stands of reeling mills are characterized by the following geometrical parameters (Fig. 3) (Matveev et al., 1970, Orlov, 2016). The geometry of a caliber is also characterized by additional parameters derived from the main parameters that are not considered.

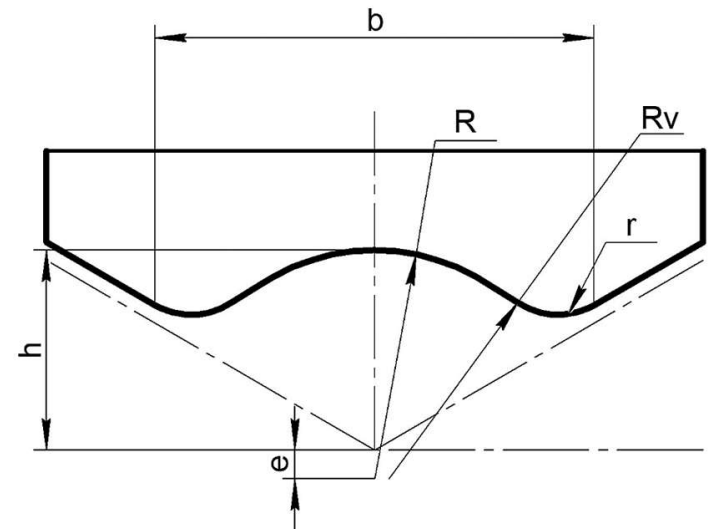

Fig. 3 The scheme of the caliber of the reeling mill

$\mathbf{R}$ - caliber radius; $\mathbf{R v}$ - the radius by which the taper of the caliber is limited;

$\mathbf{r}$ - rounding radius of the caliber; $\mathbf{h}$ - caliber height; $\mathbf{b}$ - caliber width; $\mathbf{e}$ - caliber eccentricity 
A method for determining the geometry of roll calibers of a continuous reeling mill was developed.

The values of $\mathrm{R}_{\mathrm{i}}$ correspond to the values of the external nominal radii of tubes in the calibers on rolling passes which are equal to half of the nominal tube diameters. For more uniform deformation in more loaded calibers, additional ovality is created on their base. In these cases, the parameter $e_{i}$ is introduced which shifts the application point of the radius $\mathrm{R}_{\mathrm{i}}$.

where:

$$
\begin{aligned}
& R_{i}=\frac{D_{i}+2 \cdot e_{i}}{2}, \mathrm{~mm} \\
& e_{i}=n_{i} \cdot D_{i}, \mathrm{~mm}
\end{aligned}
$$

$n_{i}$ is the eccentricity coefficient.

For the stand No. $1, \mathrm{n}_{1}=0$ is assumed, since there is no plastic deformation of the wall in thickness in this caliber and there is no need to create additional ovality of the base of the caliber. It means that $e_{1}=0$.

The main wall deformation is provided in stands 2 and 3 . And therefore we take: $n_{2}=0.015$ that is $1.5 \%$ of $D_{2} ; n_{3}=0.01$ that is $1 \%$ of $D_{3}$. The correct shape of the section of the caliber is formed in stands 4 and 5 , so we take $n_{4}=0, n_{5}=0$. The value of $R_{v i}$ depends on Rdi and on the number of the rolling pass and is determined by the formula:

$$
R v_{i}=k_{i} \cdot R_{i}, \mathrm{~mm}
$$

Rounding coefficients $\mathrm{k}$ were determined in previous studies and adopted for the calibers of the five-stand mill as follows: $k_{1}=2, k_{2}=3, k_{3}=3.3, k_{4}=2.5$, $\mathrm{k}_{5}=2.5$.

During the research of the influence of the calibers geometry on the accuracy of the tube profile and the wear rate of the mill rolls, the calibration, which is used for the rolling of a $168.3 \times 4.5 \mathrm{~mm}$ tube profile at the enterprise, was adopted as the base calibration (Table 3 ).

Table 3 Geometrical parameters of the base calibration for the production of a $168.3 \times 4.5 \mathrm{~mm}$ tube profile made of steel 20 (Calibration 1)

\begin{tabular}{|c|c|c|c|c|c|c|}
\hline \multirow{2}{*}{$\begin{array}{c}\text { Stand } \\
\text { number }\end{array}$} & \multicolumn{7}{|c|}{ Geometrical parameters of the caliber } \\
\cline { 2 - 7 } & $\mathbf{R}, \mathbf{~ m m}$ & $\mathbf{R v}, \mathbf{~ m m}$ & $\mathbf{r}, \mathbf{~ m m}$ & $\mathbf{m m}$ & $\mathbf{b}, \mathbf{~ m m}$ & $\mathbf{e , ~} \mathbf{m m}$ \\
\hline 1 & 110,1 & 191,54 & 8 & 103,2 & 165 & 6,9 \\
\hline 2 & 98,9 & 296,2 & 35,6 & 96,9 & 170,4 & 2,95 \\
\hline 3 & 94,5 & 315,5 & 26,8 & 84,5 & 166,6 & 2 \\
\hline 4 & 92 & 230 & 23,7 & 92 & 169 & 0 \\
\hline 5 & 92 & 230 & 23,7 & 92 & 169 & 0 \\
\hline
\end{tabular}

An alternative developed system of calibers is proposed to the above-mentioned calibration (Table 4).

Table 4 Geometrical parameters of the developed calibration for the production of a $168.3 \times 4.5 \mathrm{~mm}$ tube profile made of steel 20 (Calibration 2)

\begin{tabular}{|c|c|c|c|c|c|c|}
\hline \multirow{2}{*}{$\begin{array}{c}\text { Stand } \\
\text { number }\end{array}$} & \multicolumn{7}{|c|}{ Geometrical parameters of the caliber } \\
\cline { 2 - 7 } & $\mathbf{R , ~} \mathbf{m m}$ & $\mathbf{R v}, \mathbf{~ m m}$ & $\mathbf{r}, \mathbf{~ m m}$ & $\mathbf{h}, \mathbf{m m}$ & $\mathbf{b} \mathbf{~ m m}$ & $\mathbf{e , ~} \mathbf{m m}$ \\
\hline 1 & 96,5 & 195,3 & 17,817 & 96,5 & 165 & 0 \\
\hline 2 & 96,5 & 289,5 & 35,634 & 96,1 & 170,4 & 2,8 \\
\hline 3 & 94,1 & 310,5 & 26,823 & 92,1 & 166,6 & 1,8 \\
\hline 4 & 92 & 230 & 12,671 & 92 & 169 & 0 \\
\hline 5 & 92 & 230 & 12,671 & 92 & 169 & 0 \\
\hline
\end{tabular}




\section{RESULTS}

The accuracy of the geometry was estimated using the following parameters: the ratio of the taper billet radius from caliber to the base radius (R2/R1), the ratio of the taper wall thickness from calibers to the base wall thickness of the caliber (S2/S1) Fig. 4. The R2/R1 and S2/S1 ratios should tend for 1 to provide an accurate profile.

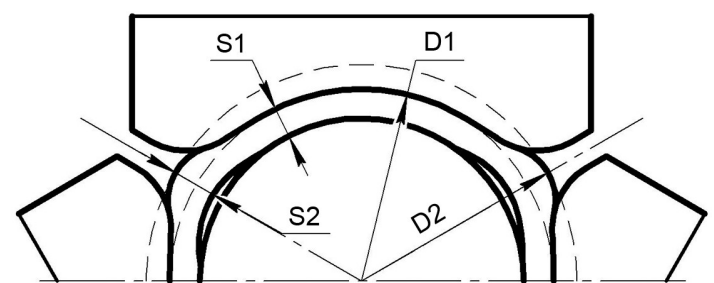

Fig. 4 The estimation scheme of geometrical parameters of the caliber

Figures 5-6 show the ratios R2/R1 and S2/S1 in the stands of a continuous reeling mill with different calibrations of mill rolls. Calibration 1 is the base system of calibers used at the enterprise, calibration 2 is the developed system of calibers.

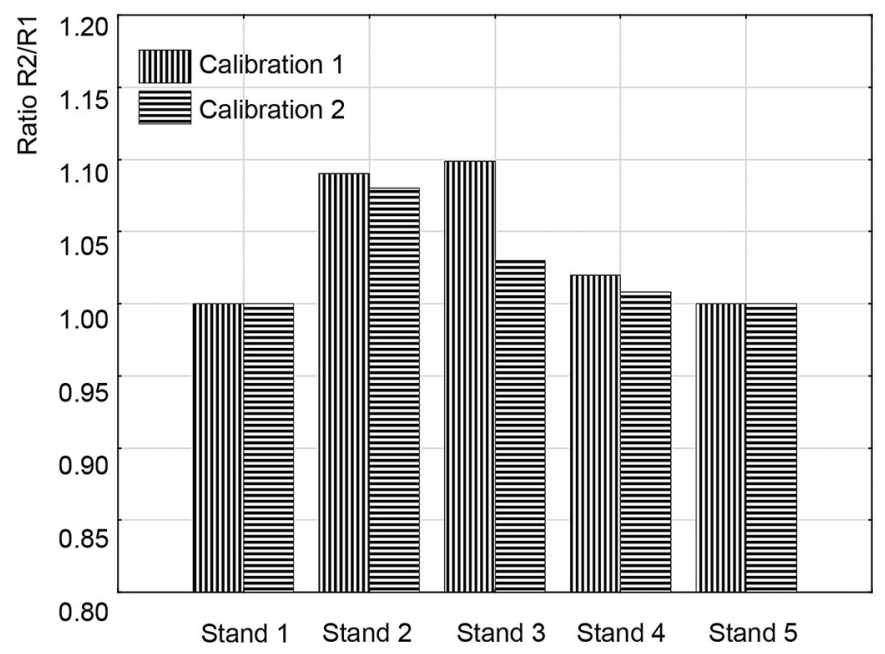

Fig. 5 The ratio of the taper billet radius from caliber to the base radius (R2/R1)

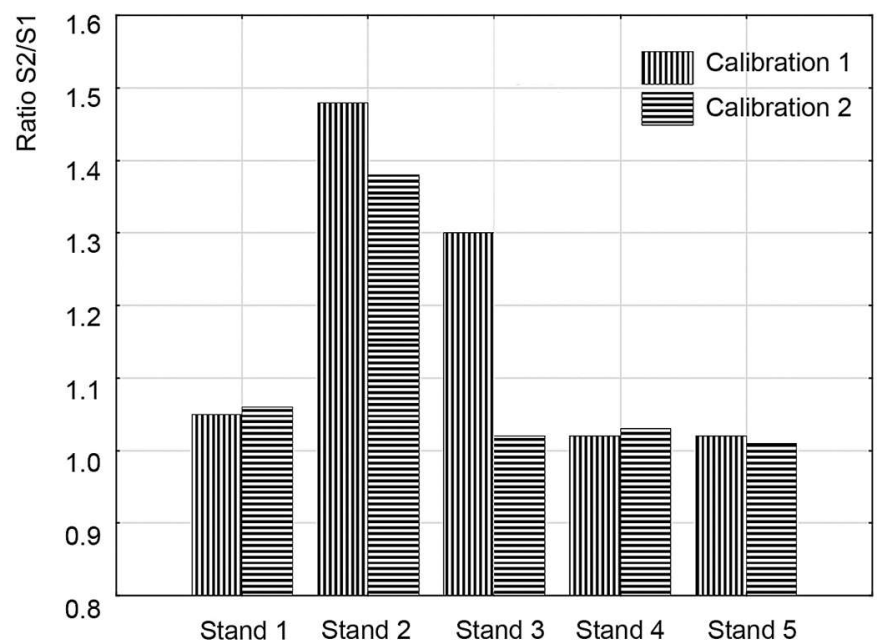

Fig. 6 The ratio of the taper wall thickness from calibers to the base wall thickness of the caliber (S2/S1) 
Figure 7 shows the results of the research of the relative deviation of the geometry of a rough tube from a specified profile.

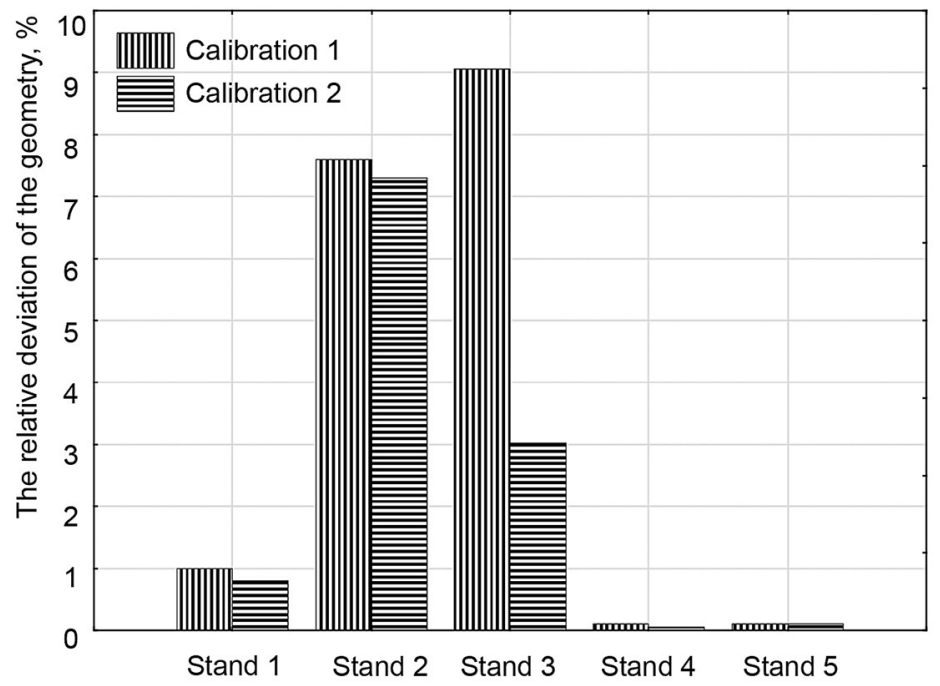

Fig. 7 The relative deviation of the profile, \%

The forces acting on the elongating mandrel and rolls during the elongating process of turning the shell into a rough tube were determined by numerical simulation. The results are presented in Table 5.

Table 5 Load acting on the rolling tool during the elongating process

\begin{tabular}{|c|c|c|c|c|c|}
\hline Calibration & \multicolumn{5}{|c|}{ Load acting on the tool, kN } \\
\cline { 2 - 6 } number & Stand 1 & Stand 2 & Stand 3 & Stand 4 & Stand 5 \\
\hline Calibration 1 & 82 & 1815 & 1669 & 1045 & 423 \\
\hline Calibration 2 & 74 & 1723 & 1604 & 998 & 382 \\
\hline
\end{tabular}

The values of effective stresses and contact pressures in the deformation zones of the stands of the reeling mill were also determined (Table 6, 7).

Table 6 Effective stresses in the deformation zones

\begin{tabular}{|c|c|c|c|c|c|}
\hline Calibration & \multicolumn{5}{|c|}{ Effective stresses, MPa } \\
\cline { 2 - 6 } number & Stand 1 & Stand 2 & Stand 3 & Stand 4 & Stand 5 \\
\hline Calibration 1 & 71 & 105 & 117 & 124 & 109 \\
\hline Calibration 2 & 69 & 104 & 109 & 118 & 99 \\
\hline
\end{tabular}

Table 7 Contact pressures in the deformation zones

\begin{tabular}{|c|c|c|c|c|c|}
\hline \multirow{2}{*}{$\begin{array}{c}\text { Calibration } \\
\text { number }\end{array}$} & \multicolumn{5}{|c|}{ Contact pressures, MPa } \\
\cline { 2 - 6 } & Stand 1 & Stand 2 & Stand 3 & Stand 4 & Stand 5 \\
\hline Calibration 1 & 148 & 491 & 652 & 485 & 329 \\
\hline Calibration 2 & 149 & 475 & 609 & 452 & 325 \\
\hline
\end{tabular}

Further research was related to the wear rate of the surface of mill rolls. Data on the wear of the contact surface of the rolls for 200 elongation cycles were obtained. Using color-coded wear distribution diagrams, the sections of the calibers of deforming stands which are the most susceptible to wear were identified. The value of the wear of the surface of mill rolls for 200 elongation cycles for different calibrations is shown in Fig. 8. 


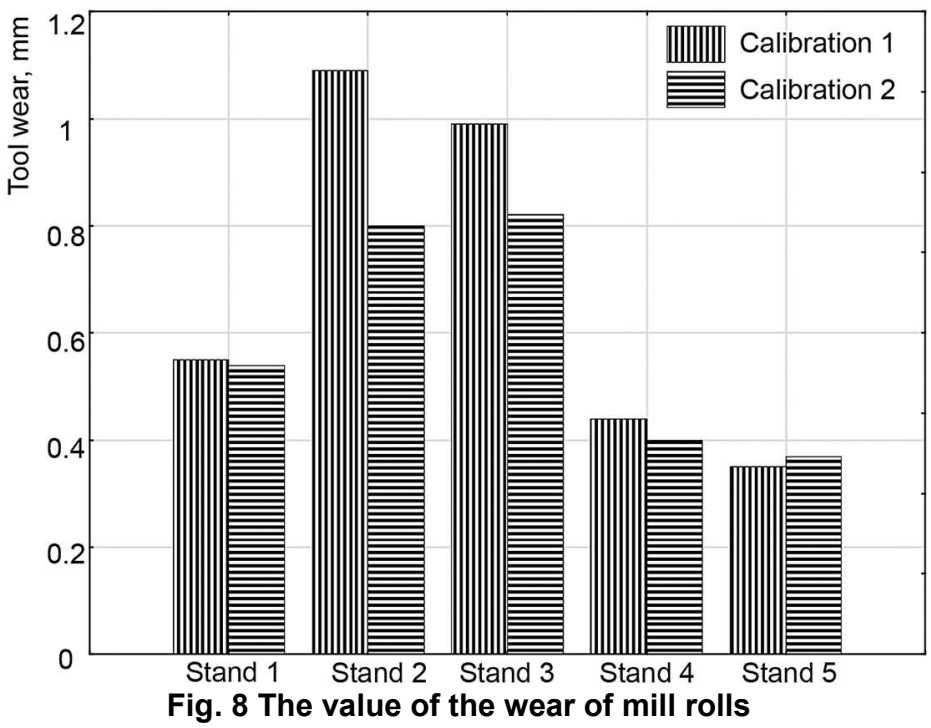

\section{DISCUSSION}

Analysis of the geometrical parameters of the billet during the elongating process makes it possible to note that the thickness of the wall of the tube on the taper of the caliber was increased on the base calibration in stands during the obtaining of the profile. That indicates wrong distribution and metal motion in the deformation zone since the caliber overfill can be observed. The greatest deviation from the form is in stands 2 and 3 due to the increase in the thickness of the tube wall on the taper of the caliber. It can lead to the formation of stresses nonuniformity on the section of the billet and the appearance of defects on the surface of the rough tube.

The application of the developed calibration allows to increase the accuracy of the obtained profile of the rough tube which will affect the quality of the resulting final profile. In addition, the developed calibration allows to reduce the load acting on the stands and to increase the resistance of the contact surface of the mill rolls.

It was also determined during the research that with the use of round calibers the greatest wear occurs along the base of the caliber due to tighter girth of the billet and less freedom of metal flow in the deformation zone. An increased wear of the elongating mandrel is also observed in the case of the tight girth of the billet. In the case of the use of oval calibers, the greatest wear is located on the tapers of calibers and on the junctions between the radii of calibers. Figure 9 highlights the areas of mill rolls that are subject to wear.

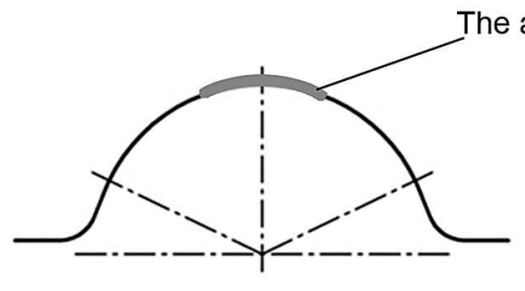

a)

Fig. 9 The area of the wear of mill rolls a) round calibers; b) oval calibers

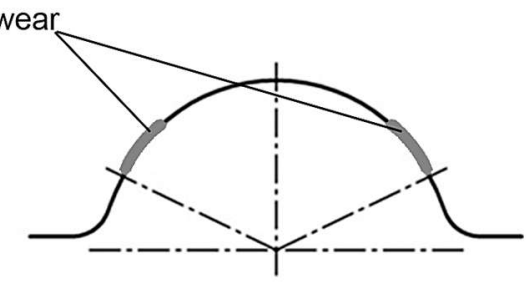

b) 
Stresses decrease in the billet is observed due to the uniform filling of calibers and free metal flow.

The use of the developed calibration allows to reduce the value of the wear of the working surface of the elongating mandrel. More uniform girth of the shell along the mandrel occurs with the use of this system of calibers, which reduces the peak values of the contact pressure and distributes uniformly the forces on the surface of the mandrel. It reduces the wear on the working surface of the elongating mandrel.

\section{CONCLUSION}

As a result of the study, the influence of the geometry of the calibers of the continuous reeling mill on the accuracy of the profile of the final rough tube and the wear of the surface of mill rolls were determined.

The main results of the work are the following:

- The influence of geometrical parameters of the rolling tool on the wear rate of the contact surface of mill rolls and the mandrel is determined.

- The influence of geometrical parameters of the rolling tool on the accuracy of the profile of obtained rough tubes is determined.

- The method of calculation of the calibers for the continuous three roll reeling mill is developed.

- The system of calibration for the continuous three roll reeling mill for obtaining the $168.3 \times 4.5 \mathrm{~mm}$ tube profile made of steel 20 , which allows to increase the resistance of the contact surface of mill rolls and to increase the accuracy of the tube profile, is developed.

Developed calibration provides more uniform calibers filling and the reduction of the resistance of metal flow during the strain process that must lead to the reduction in the loads on the rolling tool.

The use of the numerical simulation methods allows to carry out deep analysis of the stress-strain state of metal during the elongating process and to obtain adequate information about the distribution and values of strain, stresses, temperatures and energy-power parameters acting on the billet and the tool, to make it possible to estimate the wear of the rolling tool and to reduce time and costs during the designing and optimization of the elongating process.

\section{REFERENCES}

Bobarikin Yu.L., Radkin Ya. I. (2016). Adekvatnaya chislennaya model' processa raskatki gil'z na tryohvakovom nepreryvnom stane i vybor metoda ocenki iznosa instrumenta [Adequate numerical model of the shell elongating process on a three roll continuous mill and the selection of the method of the estimation of tool wear]. Sovremennye metody i tekhnologii sozdaniya i obrabotki materialov: XI Mezhdunarodnaya nauchno-tekhnicheskaya konferentsiya (Minsk, September 1416, 2016) - Minsk: PHTI NAS of Belarus;iss 3(3), pp.95. (in Russian)

Bobarikin Yu.L., Radkin Ya. I. (2017) Determination of the optimal speed of the mandrel in the continuous reeling mill using numerical simulation. Litiyo i Metallurgiya (Foundry production and metallurgy); (1): pp. 86-92. (In Russian) 
Carvalho, R.N., Ferreira, M.A.C., Santos, D.B., Barbosa, R. (2006). Simulation of the process of hot rolling of seamless tubes. Materials Science Forum, Volume 539543, pp. 4602-4607.

Chen, W., Jiang, Z., Zhang, X., Zhang, H. (2014). Heat transfer model in pipe stretchreducing process. Beijing Keji Daxue Xuebao, Volume 30, pp. 289-292.

Danchenko V.N. Kolikov A.P., Romancev B.A., Samusev C.B. (2002). Tekhnologiya trubnogo proizvodstva [Tube production technology], Moscow, Intermet inzhiniring Publ., pp. 638. (in Russian)

Dukmasov, V.G. (2001). Improvement in efficiency of operation of tube-rolling mill with automatic mill. Metallurgist, Issue 12, pp. 41-42.

Ji H., Liu J. , Wang B., Fu X, Xiao W., Hu Z. (2017). A new method for manufacturing hollow valves via cross wedge rolling and forging: Numerical analysis and experiment validation. Journal of Materials Processing Technology, Volume 240, pp. 1-11.

Jianga Y., Tang H., Zhang C. (2019). Rotation mechanics and numerical simulation of hot rolling process under asymmetric rolls. International Journal of Mechanical Sciences, Volume 151, pp. 785-796.

Li, X., Gao, L., Liu, Y.-G. (2011). Simultaneous residential location and travel mode choice estimation around rail transit station based on cross-nested logit model. Jilin Daxue Xuebao, Volume 41, pp. 1614-1617.

Matveev Yu.M., Vatkin Ya.L. (1970). Kalibrovka instrumenta trubnyh stanov [Colibration of the instrument of tube rolling mills]. Moscow, Metallurgiya Publ., pp. 480. (in Russian)

Orlov G.A. (2016). Osnovy teorii prokatki i volocheniya trub [Fundamentals of the theory of rolling and drawing tube]. Ekaterinburg, Ural. - pp. 204. (in Russian)

Pavlov D., Erpalov M. (2019). Investigation of the influence of the frequency of rotation of the rolls on the inhomogeneity of deformation during lengthwise rolling of pipes on a stub mandrel. Materials Today Proceeding, [online] Available at: https://www.sciencedirect.com/science/article/pii/S2214785319321431?via\%3Dih ub [Accessed 25 July 2019].

Pater Z., Kazanecki J., Bartnicki J. (2006). Three dimensional thermo-mechanical simulation of the tube forming process in Diescher's mill. Journal of Materials Processing Technology, Volume 177, pp. 167-170.

Pan QK., Liang G., Ling W. (2019). A multi-objective hot-rolling scheduling problem in the compact strip production. Applied Mathematical Modelling, Volume 73, pp. 327348.

Qinghua H., Zhaolun H., Yan L. (2019). Experimental and numerical investigations on residual stresses in hot-bent circular steel tube. Journal of Constructional Steel Research, Volume 161, pp. 31-46

Reggio V., McKentya F., Luc Gravela, Cortes J., Morales G., M.-A.Ladron de Guevara (2002). Computational analysis of the process for manufacturing seamless tubes. Applied Thermal Engineering, Volume 22, pp. 459-470.

Tang D., Fan X., Fang F., Li D., Peng Y., Wang H. (2018). Microstructure and mechanical properties development of micro channel tubes in extrusion, rolling and brazing. Materials Characterization, Volume 142, pp. 449-457.

Wanga F., Shuanga Y., Hua J.-H., Wanga O.-H., Suna J.-C. (2014). Explorative study of tandem skew rolling process for producing seamless steel tubes. Journal of Materials Processing Technology, Volume 214, pp. 1597-1604.

Yang C., Ma J., Hu Z. (2017). Analysis and design of cross wedge rolling hollow axle sleeve with mandrel. Journal of Materials Processing Technology, Volume 239, pp. 346-358.

Zhang, Z., Li, Y., Kong, X., Manabe, K.-I., Wang, N. (2014). Effect of intercritical annealing time on microstructure and axial mechanical properties of TRIP seamless steel tube. Steel Research International, Volume 85, pp. 632-639. 


\begin{abstract}
.
Increasing the accuracy of the geometrical parameters of tube profiles is one of the priority areas of modern tube industry. The profile of the calibers of rolls of the reeling mill exerts a significant influence over the distribution of stresses that appear in metal during the deformation process and the process of formation of the correct geometry of the obtained rough tube. The method for determining the optimal geometry of a mill roll profile has been developed. In accordance with this method the geometry of the calibers of the continuous three roll reeling mill was calculated. The research of the influence of geometrical parameters of the calibers of mill rolls on the accuracy of the obtained tube profile, the load of the rolling tool and the wear rate of the contact surface of mill rolls and a mandrel was carried out. The numerical simulation method was chosen as a research method. This method allows to carry out rather accurate analysis and to obtain reliable results on the stress-strain and thermal states of a billet during the material processing, gives the possibility to obtain numerical values of stresses, deformations, load parameters of the process, as well as allows to visualize the results that is essential for assessing the accuracy of the tube profile geometry. Numerical experiments of the elongating process of a rough tube on the three roll continuous reeling mill with different grooving of mill rolls were carried out. It was determined that using of the developed grooving will allow to get a rough tube of a higher accuracy with the minimal deviation from the shape of the profile. The use of the developed method of calculating the geometric parameters of the calibers of the continuous reeling mill will allow to obtain calibers with a high degree of resistance to wear due to the reduction of the resistance of the flow of metal and a uniform filling of the calibers in the deformation zone. The use of this grooving of mill rolls will reduce the load acting on the rolling tool during the production of hot-deformed seamless tubes.
\end{abstract}

Keywords: seamless pipes, continuous elongating process, calibers of mill rolls, accuracy of a tube profile 